ISSN: 2146-3042

DOI: $10.25095 /$ mufad.852118

\title{
Kripto Para Yatırımcılarında Finansal Risk Toleransı*
}

\author{
Nurullah UÇKUN** \\ Lokman DAL ${ }^{* * *}$
}

\section{ÖZET}

$B u$ çalışmanın amacı, kripto para yatırımcılarının finansal risk toleranslarının belirlenerek risk gruplarına göre sinıflandırlması; risk tolerans düzeylerinin demografik özellikler ve yatırım profilleri açısından ilişkisinin incelenmesidir. Çalışma kapsamında Türkiye'de 233 aktif kripto para yatırımcısından Kolayda Örnekleme Yöntemiyle veri toplanmıştır. Veri toplama aracı olarak iki bölümden oluşan anket kullanılmıştır. Katılımcıların anket sorularına verdikleri yanıtlar skorlanarak risk grupları belirlenmiștir. Yatırımcıların finansal risk tolerans ortalaması 5 puan üzerinden 3,85 olarak belirlenmiştir. 233 katılımcının \%62,2'lik kısmının ortalamanın üstünde ve yüksek risk toleransına sahip bireylerden oluştuğu belirlenmiştir.

Kripto para yatırımcılarının demografik özellikleri, yatırım profilleri ile risk toleransları arasında anlamlı bir ilişsi olup olmadığının belirlenmesi amacıyla Bağımsız Örneklem $t$ Testi ve Tek Yönlü ANOVA testleri yapılmıştır. Analiz sonuçlarına göre, yatırımclların bazı demografik özellikleri ve kripto paraya yatırım yaptıkları süre ile yatırım riski toleransları arasında anlamlı farklılıkların olduğu belirlenmiştir.

Anahtar Kelimeler: Kripto Para, Finansal Risk, Yatırımcı

JEL Sinıflandırması: C49, E22, G32

\section{Financial Risk Tolerance In Cryptocurrency Investors}

\section{ABSTRACT}

The aim of this study is to determine financial risk tolerances of crypto currency investors and to classify them according to risk groups, and also determine the relationship between these levels of tolerance in terms of demographic characteristics and investment profiles. Within the scope of the study, the data was collected from 233 active cryptocurrency investors in Turkey by Convenience Sampling Method. A questionnaire consisting of two parts was used as data collection instrument. The responses of the participants to the survey questions were scored and risk groups were determined. The average financial risk tolerance of the investors was determined as 3.85 out of 5 points. It was determined that \%62.2 of the 233 participants consisted of individuals above the average and having high risk tolerance.

In order to determine whether there is a significant relationship between demographic characteristics, investment profiles and risk tolerances of cryptocurrency investors, Independent Sample $t$ Test and One-Way ANOVA tests were conducted. According to the results of the analysis, it was determined that there were significant differences between some demographic characteristics of the investors, the time they invest in cryptocurrency and the tolerance of investment risk.

Keywords: Crypto Currency, Financial Risk Tolerance, Investor

Jel Classification: C49, E22, G32

\footnotetext{
* Makale Gönderim Tarihi: 6.2.2020, Makale kabul tarihi: 17.04.2020, Makale Türü: Nicel araştırma

** Prof.Dr., Eskişehir Osmangazi Üniversitesi, İktisadi ve İdari Bilimler Fakültesi, nuckun@ogu.edu.tr, ORCID: 0000-0001-5073-5644.

*** Eskişehir Osmangazi Üniversitesi, Sosyal Bilimler Enstitüsü, lokmandal1986@gmail.com, ORCID: 00000002-8932-8744.
} 


\section{GİRIŞ}

Kripto paralar, son yıllarda yatırımcıların ilgi odağı olan, sermayenin küresel anlamda serbestçe hareket edebilmesine imkân tanıyan finansal enstrümanlardır. 2008 yılında Satoshi Nakamoto takma ismiyle blockchain sistemi üzerine kurulu olarak icat edilen Bitcoin, kripto paraların başında gelmektedir. Bitcoin dışında Ethereum, Ripple, Litecoin vb. kripto paralar da bulunmaktadır. 2019 yılı Temmuz ayı itibariyle küresel anlamda dolaşımda olan kripto para sayısı 2.704 çeşit olup, yaklaşık 265 milyar $\$$ piyasa değerine sahiptir (https://tr.investing.com/crypto/currencies, 2019). Dünya üzerinde herhangi bir otoriteye veya ülkeye bağlı olmayan, aracısız ve bireyden bireye (Peer-to-Peer-P2P) para transferine imkan tanıyan kripto para sistemi, bazı dezavantajları olmasına rağmen sağladığı kolaylık ve avantajları sebebiyle tasarruf sahiplerince oldukça rağbet görmektedir.

İcat edildiği ilk dönemlerde bazı yasadışı işlemlerde değişim aracı olarak kullanılan Bitcoin'in günümüzdeki meşruluğu halen tartışmalı bir konudur. Birçok ülke, söz konusu kripto parayı sakıncaları sebebiyle değişim aracı olarak görmemektedir. Hatta bazı ülkeler kripto paralarla yapılan işlemleri yasaklamaktadır. Kripto para sisteminin çalışma prensibinin net olmaması, piyasanın oldukça volatil, istikrarsız ve spekülatif bir yapıya sahip olması, bazı yasadışı işlerde (kara para aklama, silah kaçakçılığı vb.) kullanılması, elektronik ortamda yapılabilecek saldırılara karşı güvenliğinin tam anlamıyla ispatlanamamış olması vb. riskler, ülkelerin ve merkez bankalarının kripto parayı meşru görmemelerindeki etkenlerden bazılarıdır. Bahsi geçen bu sakıncalarının yanı sıra kripto para sisteminin üstünlükleri de bulunmaktadır. Bitcoin'in sınırlı sayıda olması, yapılan işlemlerin elektronik ortamda tüm kullanıcıların kayıt defterine tutuluyor olması ve kayıtların değiştirilememesi, para transferinde üçüncü kişileri veya kurumları aradan çıkararak işlem maliyetini sıfıra indirmesi, ülkeler arası para transferinde dahi aracısız ve çok hızlı işlem sağlaması kripto para sisteminin yatırımcılarına sağladığı başlıca avantajlardandır.

Lidyalılar'ın ilk parayı icat edişinden günümüze dek kullanılan tüm paralar madeni veya banknot şeklinde basılmış, fiziksel anlamda değiş tokuş aracı olarak kullanılmıştır. Ancak kripto para sistemi, yukarıda bahsi geçen yapısı itibariyle geleneksel anlamda "para" kavramından farklı bir sistemdir. Fiziksel bir karşılığı olmayan, bir veri tabanında şifrelenerek yalnızca elektronik olarak transferi sağlanan kripto paralar, yatırımcıları tarafından yeterli tedbir alınmaması halinde elektronik ortamda yapılabilecek küresel saldırılara ve hırsızlıklara karşı savunmasız kalabilmektedirler. Özellikle küresel hacker saldırılarının, oltalama olaylarının artış gösterdiği günümüzde elektronik cüzdanların güvenliği yatırımcılar için önem taşımaktadır.

Kripto para piyasası, oldukça oynak ve spekülatif bir yapıya sahiptir. Yatırımcılarına çok kısa sürede büyük kazançlar sağlayabildikleri gibi kısa sürede büyük kayıplara da sebep olabilmektedirler. Kimliği tam olarak bilinmeyen bazı firmalar tarafindan spekülatif amaçlı piyasaya sürülen ve geleceği şüpheli "İlk Coin Arzları (ICO-Initial Coin Offering)" şeffaflıktan öte olabilmekte, saadet zinciri (ponzi) taktiğiyle başlangıçta yatırımcılarına çok kazandırıyor gibi gözükse de sonrasında daha çok kaybettirebilmekte ve piyasadan kaybolabilmektedir.

Tüm olumsuzluklarına rağmen, günümüzde kripto para piyasasına olan talep hızla artmaktadır. Birçok yatırımcı ve ekonomiste göre, piyasanın gelecekte sahip olacağı hacim ve 
sağladığ1 avantajlar umut vaat etmektedir. Bununla birlikte, kripto para piyasasına şüpheyle yaklaşan, sistemi, sürekli şişen ve gelecekte patlayacak bir "balon” olarak gören, taşıdığı riskleri, suiistimale açık olması, güvencesiz olması ve denetimsiz bir yapıya sahip olması sebebiyle para olarak nitelendirmeyen ekonomistler ve hükümetler bulunmaktadır. Böylesi bir ortamda, kripto paralara yatırım yapan bireylerdeki Finansal Risknın merak konusu olabileceği değerlendirilmektedir.

$\mathrm{Bu}$ çalışmanın amacı, kripto para yatırımcılarının finansal risk tolerans düzeylerini belirleyerek risk gruplarına ayırmaktır. Yatırımcıların demografik özellikleri, yatırım profilleri ile risk tolerans düzeyleri arasında anlamlı bir ilişki olup olmadığının incelenmesi çalışmanın bir diğer amacıdır. Çalışmanın amacı doğrultusunda, Türkiye'de aktif olarak kripto para yatırımı yapan bireyler evren olarak belirlenmiştir. Evrendeki tüm birimlere ulaşmak mümkün olmadığından örneklemeye başvurulmuş, kolayda örnekleme yöntemiyle 233 aktif kripto para yatırımcısından veri toplanmıştır. Veri toplama aracı olarak iki bölümden oluşan anket kullanılmıştır. Elde edilen verilerle SPSS 22 paket programı vasıtasıyla betimsel ve çıkarımsal analizler yapılmıştır.

\section{LITERATÜR}

Dünya çapında kripto para kavramının literatüre girmesi, 2009 yılında Satoshi Nakamoto takma isimli kişinin "Bitcoin: A Peer-to-Peer Electronic Cash System” isimli makalesiyle gerçekleşmiştir. Öncelikle "darknet” denilen internetin derinliklerinde birçok yasadışı alış-verişte değişim aracı olarak kullanılan Bitcoin, söz konusu makale ile dünyaya tanıtılmıştır. Önceleri bireysel yatırımcılar tarafından kabul gören Bitcoin, giderek popülerlik kazanmış, bazı kurum ve kuruluşlar Bitcoin'i ödeme aracı olarak kabul etmişlerdir. Sonrasında birçok dijital para ortaya çıkmış ve kripto para piyasası oluşmuştur.

Türk literatüründe ve yabancı literatürde kripto para piyasasını konu alan sınırlı sayıda akademik çalışmanın yapıldığ görülmektedir. Söz konusu akademik çalışmaların çoğu Bitcoin ve kripto para piyasasının yapısı ve geleceği (Sönmez, 2014; Gültekin ve Bulut, 2016; Urquhart, 2016; Fry ve Cheah, 2016; Gültekin, 2017; Khalilov vd., 2017; Pirinççi, 2018; Bouri vd., 2019), küresel ekonomiye ve piyasalara etkileri (Atik vd., 2015; Koçoğlu vd,, 2016; Bilir ve Çay, 2016; Dirican ve Canöz, 2017; Göde ve Küçükşahin, 2017), yasalara ve mevzuata uyarlanabilirliği (Yurtçiçek, 2015; Yüksel, 2015; Aslantaş Ateş, 2016; Dizkırıcı ve Gökgöz, 2018; Kaplanhan; 2018) ile ilgilidir.

Literatürde kripto para yatırımcılarını konu alan sınır sayıda çalışma bulunmaktadır. Söz konusu çalışmalardan bazıları şöyle özetlenebilir: Sütçü ve Aytekin (2018), bitcoin madenciliği, alım-satımı yapan veya ticaretini takip eden kişilerin girişimcilik düzeylerini araştırmışlardır. Örneklem olarak konu ile ilgili Twitter kullanıcılarını seçmişlerdir. Araştırma sonuçları, Bitcoin madenciliği, alım-satımı yapan veya ticareti ile ilgilenen kişilerde girişimcilik puanlarının yüksek düzeyde olduğunu göstermiştir. Pelster vd. (2019) bireylerin kripto paralara yatım yapmaları altında yatan nedeni araştırmışlardır. Yatırımcıların ilk yaptıkları kripto para yatırımlarını incelemişler ve söz konusu yatırımlarını heyecan arama amaçlı yaptıklarını belirlemişlerdir. Ballis ve Drakos (2019) en popüler 6 kripto para üzerinde yatırımcıların sürü davranışında bulunup bulunmadıklarını test etmişlerdir. Bu bağlamda belirli bir döneme ait günlük verileri analiz etmişlerdir. Analiz sonucunda kripto para 
yatırımcılarının irrasyonel davrandıklarını, kendi kararlarından ziyade başkalarının fikirleriyle hareket ederek sürü davranışı gösterdiklerini belirlemişlerdir.

Anlaşılacağı üzere, literatürde kripto para yatırımcılarının farklı davranışsal özelliklerini belirlemeye yönelik sınırlı sayıda çalışma bulunmakla birlikte söz konusu yatırımcıların finansal risk toleranslarını belirlemeye yönelik yapılmış herhangi bir çalışmaya rastlanmamıştır. Bu çalışma, yalnızca kripto para yatırımcılarının finansal risk toleranslarının belirlenmesi amacıyla literatürde yapılan ilk çalışma olması sebebiyle önem taşımakta ve diğer çalışmalardan farklılık göstermektedir.

\section{YÖNTEM}

$\mathrm{Bu}$ çalışma, kripto para yatırımcılarının finansal risk toleranslarının belirlenerek söz konusu özelliklerin demografik değişkenler itibariyle farklılıklarının belirlenmesi amacıyla yapılmıştır. Çalışmanın evrenini, Türkiye'de aktif olarak kripto para yatırımı yapan bireyler oluşturmaktadır. Kripto para yatırımı yapan bireylerin aynı zamanda farklı kripto para alımsatım siteleri üzerinde işlem yapıyor olması ve kayıtlarının tutulduğu resmi bir altyapı olmaması sebebiyle evrendeki birim sayısına ulaşılamamıştır. Bu sebeple örnekleme yapılmış, kolayda örnekleme yöntemiyle veri toplanmıştır. Veri toplama aracı olarak on-line anket kullanılmıştır. Bu doğrultuda, Türkiye'de kripto para yatırımcılarına yönelik oluşturulmuş çeşitli forum ve sosyal medya kanalları üzerinde on-line anket linki paylaşılmıştır. Araştırma 2019 yılı Ağustos ayı içerisinde yapılmıştır. Söz konusu forum ve sosyal medya kanallarına üye olan bireylerden anket doldurmaları talep edilmiş, toplam 233 aktif kripto para yatırımcısından veri toplanmıştır.

Araştırmada kullanılan anket, iki bölümden oluşmaktadır. Birinci bölümde, kripto para yatırımcılarının demografik özellikleri (cinsiyet, medeni hal vb.) ile genel olarak kripto para yatırım profillerinin belirlenmesine yönelik sorular bulunmaktadır. İkinci bölümde ise, yatırımcıların finansal risk toleranslarını belirlemeye yönelik Grable ve Lytton (1999a) tarafından geliştirilen, 13 adet çoktan seçmeli sorudan oluşan "Risk Toleransı Ölçeği" kullanılmıştır. ${ }^{1}$ Risk Toleransı Ölçeği, içeriğinde finansal risk, yatırım riski ve spekülatif risk bileşenlerine ait çoktan seçmeli sorular içeren bir ölçektir. (Orçun; 2015:100). Risk Tolerans1 Ölçeği, araştırmanın amacına yönelik olarak kripto para yatırımcıları için uyarlanmıştır. Ölçekte, yatırımcıların finansal risk toleranslarını ölçmeye yönelik 5, yatırım riski toleranslarını ölçmeye yönelik 5 ve spekülatif risk toleranslarını ölçmeye yönelik 3 soru bulunmaktadır. Ölçekteki soru numaraları, risk toleransı bileşenleri ve skorlamaya ilişkin çizelge Tablo 1'de gösterilmiştir.

\footnotetext{
${ }^{1}$ Kaynak: https://njaes.rutgers.edu/money/assessment-tools/investment-risk-tolerance-quiz.pdf (Erişim Tarihi: 14.05.2019)
} 
Tablo 1. Finansal Risk Soruları ve Cevap Seçeneklerine Ait Puanlar

\begin{tabular}{|c|c|c|c|c|c|}
\hline \multirow{2}{*}{$\begin{array}{c}\text { Soru } \\
\text { Numaraları }\end{array}$} & \multirow{2}{*}{ Risk Toleransı Bileşeni } & \multicolumn{4}{|c|}{ Seçenekler } \\
\hline & & A & B & C & D \\
\hline 1. & Finansal Risk & 4 & 3 & 2 & 1 \\
\hline 2. & Spekülatif Risk & 1 & 2 & 3 & 4 \\
\hline 3. & Finansal Risk & 1 & 2 & 3 & 4 \\
\hline 4. & Yatırım Riski & 1 & 2 & 3 & - \\
\hline 5. & Spekülatif Risk & 1 & 3 & - & - \\
\hline 6. & Yatırım Riski & 1 & 2 & 3 & - \\
\hline 7. & Finansal Risk & 1 & 2 & 3 & 4 \\
\hline 8. & Finansal Risk & 1 & 2 & 3 & 4 \\
\hline 9. & Yatırım Riski & 1 & 2 & 3 & 4 \\
\hline 10. & Yatırım Riski & 1 & 2 & 3 & 4 \\
\hline 11. & Yatırım Riski & 1 & 2 & 3 & - \\
\hline 12. & Spekülatif Risk & 1 & 3 & - & - \\
\hline 13. & Finansal Risk & 1 & 2 & 3 & 4 \\
\hline
\end{tabular}

Kaynak: Grable ve Lytton, 1999b:3

Kripto para yatırımcılarının finansal risk toleranslarını belirlemek için Risk Toleransı Ölçeği'ne verdikleri yanıtlardan elde edilen puanlar Tablo 1'e göre toplanarak hesaplanmıştır. Her bir yatırımcının risk tolerans skoru, Grable ve Lytton (1999b:3) tarafindan belirlenen risk gruplarına ve referans skor aralıklarına göre değerlendirilmiştir. Toplam skorlara göre yatırımcıların değerlendirildiği risk grupları, Tablo 2'de belirtilmiştir.

Tablo 2. Risk Grupları ve Skor Aralıkları

\begin{tabular}{|l|l|c|}
\hline \multicolumn{1}{|c|}{ Risk Grupları } & \multicolumn{1}{|c|}{ Risk Grubu Tanımı } & Referans Skor Aralığı \\
\hline Risk Grubu-1 & Düşük Risk Toleransı (Muhafazakâr Yatırımcı) & 18 ve Altı \\
\hline Risk Grubu-2 & Ortalamanın Altında Risk Toleransı & $19-22$ \\
\hline Risk Grubu-3 & Ortalama/Ölçülü Risk Toleransı & $23-28$ \\
\hline Risk Grubu-4 & Ortalamanın Üstünde Risk Toleransı & $29-32$ \\
\hline Risk Grubu-5 & Yüksek Risk Toleransı (Agresif Yatırımcı) & 33 ve Üstü \\
\hline
\end{tabular}

Kaynak: Grable ve Lytton, , 1999b:3

Yatırımcılar, toplam skorlarına göre "Risk Grubu 1-Düşük Risk Tolerans1 (Muhafazakâr Yatırımc1)” ve "Risk Grubu 5-Yüksek Risk Toleransı (Agresif Yatırımcı)” olmak üzere 1 ile 5 arasındaki risk gruplarına göre sınıflandırılmışlardır. Yatırımcıların bazı demografik özellikleri ve yatırımcı profilleri ile risk grupları arasında anlamlı farklılığın olup olmadığının belirlenmesi amacıyla Bağımsız Örneklem t Testi ve Tek Yönlü ANOVA Testleri uygulanmıştır. 


\section{BULGULAR}

Araştırmaya katılan kripto para yatırımcılarına ait demografik özellikler Tablo 3'te gösterilmiştir.

Tablo 3. Kripto Para Yatırımcılarının Demografik Özelliklerine Göre Dağılımları

\begin{tabular}{|c|c|c|c|c|c|c|c|}
\hline Değişken & Değişken Tanımı & Frekans & Yüzde & Değişken & Değişken Tanımı & Frekans & Yüzde \\
\hline \multirow{2}{*}{ Cinsiyet } & Erkek & 214 & 91,8 & \multirow{2}{*}{$\begin{array}{l}\text { Medeni } \\
\text { Hal }\end{array}$} & Evli & 123 & 52,8 \\
\hline & Kadın & 19 & 8,2 & & Bekâr & 110 & 47,2 \\
\hline \multirow{5}{*}{ Yaş } & 20'den Az & 3 & 1,3 & \multirow{7}{*}{ Meslek } & Kamu Çalışanı & 74 & 31,8 \\
\hline & 20-30 Aras1 & 72 & 30,9 & & Özel Sektör Çalışanı & 82 & 35,2 \\
\hline & 30-40 Aras1 & 110 & 47,2 & & Emekli & 4 & 1,7 \\
\hline & 40-50 Aras1 & 39 & 16,7 & & Serbest Meslek & 15 & 6,4 \\
\hline & 50 Ve Üzeri & 9 & 3,9 & & Kendi İşinde Çalışan & 28 & 12,0 \\
\hline \multirow{4}{*}{$\begin{array}{l}\text { Çocuk } \\
\text { Sayısı }\end{array}$} & Yok & 128 & 54,9 & & İşsiz & 17 & 7,3 \\
\hline & 1 Çocuk & 45 & 19,3 & & Diğer & 13 & 5,6 \\
\hline & 2 Çocuk & 47 & 20,2 & \multirow{6}{*}{$\begin{array}{l}\text { Aylık } \\
\text { Net Gelir }\end{array}$} & 2.500 TL'den Az & 29 & 12,4 \\
\hline & 3 Çocuk Ve Üzeri & 13 & 5,6 & & $2.500 \mathrm{TL}-5.000 \mathrm{TL}$ & 67 & 28,8 \\
\hline \multirow{5}{*}{ Eğitim } & İlköğretim & 5 & 2,1 & & $5.000 \mathrm{TL}-7.500 \mathrm{TL}$ & 55 & 23,6 \\
\hline & Lise & 41 & 17,6 & & $\begin{array}{l}\text { 7.500 TL - } 10.000 \\
\text { TL }\end{array}$ & 43 & 18,5 \\
\hline & $\begin{array}{l}\text { Ön Lisans / } \\
\text { Yüksekokul }\end{array}$ & 23 & 9,9 & & \begin{tabular}{|l|}
$10.000 \mathrm{TL}-12.500$ \\
$\mathrm{TL}$
\end{tabular} & 15 & 6,4 \\
\hline & Üniversite & 131 & 56,2 & & 12.500 TL Ve Üzeri & 24 & 10,3 \\
\hline & Lisansüstü & 33 & 14,2 & \multicolumn{4}{|c|}{$n=233$} \\
\hline
\end{tabular}

Tablo 3'ten görüldüğ̈̈ gibi; 233 kripto para yatırımcısının \%91,8'i erkek, \%8,2'si kadındır. Evli $(\% 52,8)$ ve bekâr $(\% 47,2)$ yatırımcıların oranları birbirlerine oldukça yakındır. Yaş grupları açısından değerlendirildiğinde, 233 yatırımcıdan 110'unun 30-40 yaş aralığında olduğu dikkat çekmektedir. Tablo 1'de dikkat çeken bir diğer önemli veri ise yatırımcıların yarıdan fazlasının $(\% 54,9)$ çocuk sahibi olmaması ve üniversite mezunu bireyler $(\% 56,2)$ olmalarıdır. Yatırımcılar içinde kamu ve özel sektör çalışanları, örneklemin büyük bir kısmını (\%67) oluşturmakta, emekli yatırımcıların oranının $(\% 1,7)$ oldukça düşük olduğu görülmektedir.

Kripto para yatırımcılarının yatırım yaptıkları süreler Tablo 4'te gösterilmiştir. Buna göre, yatırımcıların büyük bir çoğunluğunun kripto paranın Türkiye'de popülerlik kazandığı son 3 yıllık zaman diliminde yatırım yaptıkları Tablo 4'ten anlaşılmaktadır. 
Tablo 4. Kripto Para Yatırımcılarının Yatırım Sürelerine Göre Dağılımları

\begin{tabular}{|l|l|c|c|}
\hline \multicolumn{1}{|c|}{ Soru } & \multicolumn{1}{|c|}{ Seçenekler } & Frekans & Yüzde \\
\hline \multirow{4}{*}{$\begin{array}{l}\text { Ne kadar süredir kripto para } \\
\text { yatırımı yapmaktasınız? }\end{array}$} & 1 Y1ldan Az & 53 & 22,7 \\
\cline { 2 - 4 } & 1 Y11 - 3 Y11 & 157 & 67,4 \\
\cline { 2 - 4 } & 3 Yil - 5 Y11 & 18 & 7,7 \\
\cline { 2 - 4 } & 5 Yil ve Üzeri & 5 & 2,1 \\
\hline
\end{tabular}

Kripto para yatırımcılarına yöneltilen "Kripto para yatırım portföyünüzü hangi sıklıkla gözden geçiriyorsunuz?" sorusuna alınan yanıtların dağılımları Tablo 5'te gösterilmektedir. Yatırımcıların \%68,7'lik kısmının yatırımlarını her gün gözden geçirdikleri Tablo 5'ten anlaşılmaktadır.

Tablo 5. Kripto Para Yatırımcılarının Yatırım Portföyü Takip Sıklıklarına Göre Dağılımları

\begin{tabular}{|l|l|c|c|}
\hline \multicolumn{1}{|c|}{ Soru } & \multicolumn{1}{|c|}{ Seçenekler } & Frekans & Yüzde \\
\hline \multirow{4}{*}{$\begin{array}{l}\text { Kripto para yatırım portföyünüzü } \\
\text { hangi sıklıkla gözden geçiriyorsunuz? }\end{array}$} & Her Gün & 160 & 68,7 \\
\cline { 2 - 4 } & Haftada Bir Kere & 23 & 9,9 \\
\cline { 2 - 4 } & Haftada Birkaç Kere & 14 & 6,0 \\
\cline { 2 - 4 } & Ayda Bir Kere & 17 & 7,3 \\
\cline { 2 - 4 } & Ayda Birkaç Kere & 13 & 5,6 \\
\cline { 2 - 4 } & Diğer & 6 & 2,6 \\
\hline
\end{tabular}

Yatırımcıların kripto para yatırım tercihlerine göre dağılımları Tablo 6'da gösterilmektedir. Buna göre, yatırımcıların \% 47,6'lık kısmı hem Bitcoin ${ }^{2}$, Ethereum ${ }^{3}$, Ripple $^{4}$, Litecoin ${ }^{5} \mathrm{vb}$. öncü kripto paralara hem de diğer alt sanal paralara yatırım yaptıkları anlaşılmaktadır.

\footnotetext{
22008 yılında Satoshi Nakamoto rumuzlu bir kişi ya da ekibin yayınladığı doküman ile hayata geçen, sahibi ve merkezi olmayan, aracısız bir ödeme aracı ve para birimidir. Herhangi bir kurum ya da kuruluşa bağlı değildir. Temsilciliği ya da bayileri yoktur. Kaynak: https://www.btcturk.com/bilgi-platformu/bitcoin-nedir (Erişim Tarihi: 05.04.2020)

${ }^{3}$ Ethereum projesi, bir kripto para birimi, ödeme yöntemi ve merkeziyetsiz uygulama platformunu bir araya getiren bir kripto para işletim sistemidir. Kaynak: https://pro.btcturk.com/faydali-bilgiler/ethereum-nedir (Erişim Tarihi: 05.04.2020)

${ }^{4}$ Ripple ağ 1 (RippleNet) üzerinde değer transfer etmeyi sağlayan bir kripto paradır. RippleNet'e üye banka ve finans kuruluşları arasında uluslararası para transferlerini anlık ve düşük maliyetli olarak gerçekleştirmeyi amaçlayan, SWIFT’e alternatif bir ödeme ağıdır. Kaynak: https://pro.btcturk.com/faydali-bilgiler/xrp-nedir (Erişim Tarihi: 05.04.2020)

${ }^{5}$ Litecoin, dünya genelinde herkes için yok denilebilecek az düzeyde olan maliyetle para transferi yapmaya olanak sağlayan bir kripto para birimidir. Diğer alt coinler gibi herhangi bir merkezi olmayan Litecoin, açık kaynak kodlu küresel bir ödeme sistemidir.Kaynak: https://www.hurriyet.com.tr/teknoloji/litecoin-nedir-40675848 (Erişim Tarihi: 05.04.2020)
} 
Tablo 6. Kripto Para Yatırımcılarının Yatırım Tercihlerine Göre Dağılımları

\begin{tabular}{|l|l|c|c|}
\hline \multicolumn{1}{|c|}{ Soru } & \multicolumn{1}{|c|}{ Seçenekler } & Frekans & Yüzde \\
\hline \multirow{4}{*}{$\begin{array}{l}\text { Yatırımlarınızı hangi tür kripto } \\
\text { paralar üzerinde } \\
\text { değerlendiriyorsunuz? }\end{array}$} & $\begin{array}{l}\text { Bitcoin, Ethereum, Ripple, } \\
\text { Litecoin vb. Kripto Paralar. }\end{array}$ & 82 & 35,2 \\
\cline { 2 - 4 } & Diğer Alt Sanal Paralar. & 40 & 17,2 \\
\cline { 2 - 4 } & $\begin{array}{l}\text { Her İki Tür Üzerinde De } \\
\text { Değerlendiriyorum. }\end{array}$ & 111 & 47,6 \\
\hline
\end{tabular}

Yatırımcıların yatırım portföylerindeki kripto para sayılarına göre dağılımları Tablo 7'de gösterilmiştir. Buna göre yatırımcıların \%30,9'luk kısmının 5 ve üzerinde farklı kripto paraya yatırım yaptıkları anlaşılmaktadır. 5'ten az sayıda kripto paraya yatırım yapanların yüzdelik oranlarının ise birbirlerine oldukça yakın olduğu görülmektedir.

Tablo 7. Kripto Para Yatırımcılarının Yatırım Yaptıkları Kripto Para Sayılarına Göre Dağılımları

\begin{tabular}{|l|l|c|c|}
\hline \multicolumn{1}{|c|}{ Soru } & \multicolumn{1}{|c|}{ Seçenekler } & Frekans & Yüzde \\
\hline \multirow{4}{*}{$\begin{array}{l}\text { Mevcut kripto para yatırım } \\
\text { portföyünüzde kaç farklı sanal para } \\
\text { mevcuttur? }\end{array}$} & 1 & 48 & 20,6 \\
\cline { 2 - 4 } & 2 & 43 & 18,5 \\
\cline { 2 - 4 } & 3 & 34 & 14,6 \\
\cline { 2 - 4 } & 4 & 36 & 15,5 \\
\cline { 2 - 4 } & 5 ve Üzeri & 72 & 30,9 \\
\hline
\end{tabular}

Yatırımcılara, kripto para yatırımlarını yönlendirmede tercih ettikleri temel bilgi kaynakları sorulmuş ve birden fazla seçeneği seçebilecekleri belirtilmiştir. Buna göre, 233 yatırımcının \%37,8'lik kısmı yatırımlarını yönlendirirken internet, TV ve medyaya başvurmaktadır. Bununla birlikte, \%31,3'lük kısmının da şahsi tecrübelerinden faydalandığı Tablo 8'den anlaşılmaktadır.

Tablo 8. Kripto Para Yatırımcılarının Yatırımlarını Yönlendirmede Temel Bilgi Kaynaklarına Göre Dağılımları

\begin{tabular}{|l|l|c|c|}
\hline \multicolumn{1}{|c|}{ Soru } & \multicolumn{1}{|c|}{ Seçenekler } & Frekans & Yüzde \\
\hline \multirow{4}{*}{$\begin{array}{l}\text { Kripto para yatırımlarınızı } \\
\text { yönlendirmede temel bilgi } \\
\text { kaynaklarınız nelerdir? }\end{array}$} & Tecrübelerim & 146 & 31,3 \\
\cline { 2 - 4 } & Arkadaşlarım & 59 & 12,7 \\
\cline { 2 - 4 } & İnternet, TV, Medya & 176 & 37,8 \\
\cline { 2 - 4 } & $\begin{array}{l}\text { Süreli Yayınlar (Gazete, Finans, } \\
\text { Ekonomi Dergileri vb.) }\end{array}$ & 68 & 14,6 \\
\cline { 2 - 4 } & Diğer & 17 & 3,6 \\
\hline
\end{tabular}

Yatırımcıların, 13 sorudan oluşan Finansal Risk Toleransı anketinden elde edilen skorları hesaplanmış, elde edilen sonuçlara göre dahil oldukları risk grupları 
belirlenmiştir. Tablo 9, kripto para yatırımcılarının risk gruplarına göre dağılımlarını göstermektedir.

Tablo 9. Kripto Para Yatırımcılarının Risk Gruplarına Göre Dağılımları

\begin{tabular}{|l|l|c|c|c|}
\hline \multicolumn{1}{|c|}{ Risk Grupları } & \multicolumn{1}{|c|}{ Risk Grubu Tanımı } & $\begin{array}{c}\text { Referans Puan } \\
\text { Aralığı }\end{array}$ & Frekans & Yüzde \\
\hline Risk Grubu-1 & Düşük Risk Toleransı (Muhafazakâr Yatırımcı) & 18 ve Altı & 1 &, 4 \\
\hline Risk Grubu-2 & Ortalamanın Altında Risk Toleransı & $19-22$ & 8 & 3,4 \\
\hline Risk Grubu-3 & Ortalama/Ölçülü Risk Toleransı & $23-28$ & 79 & 33,9 \\
\hline Risk Grubu-4 & Ortalamanın Üstünde Risk Toleransı & $29-32$ & 83 & 35,6 \\
\hline Risk Grubu-5 & Yüksek Risk Toleransı (Agresif Yatırımcı) & 33 ve Üstü & 62 & 26,6 \\
\hline Ort.= 3,85 & s.d. $=\mathbf{8 7 2}$ & & 233 & 100 \\
\hline
\end{tabular}

Tablo 9'a göre, ankete katılan 233 kripto para yatırımcısının \%4'ü düşük risk toleransına, \%3,4'ü ortalamanın altında risk toleransına, \%33,9'u ortalama/ölçülü risk toleransına, \%35,6's1 ortalamanın üstünde risk toleransına ve \%26,6's1 yüksek risk toleransına sahiptir. Diğer taraftan, katılımcıların risk tolerans ortalamaları 5 puan üzerinden 3,85 olarak belirlenmiştir. Yatırımcıların \%62,2'lik kısmının ortalamanın üstünde ve yüksek risk toleransına sahip bireylerden oluştuğu da Tablo 9'dan anlaşılmaktadır.

Katılımcıların dâhil oldukları risk gruplarına ait histogram Şekil 1'de gösterilmektedir.

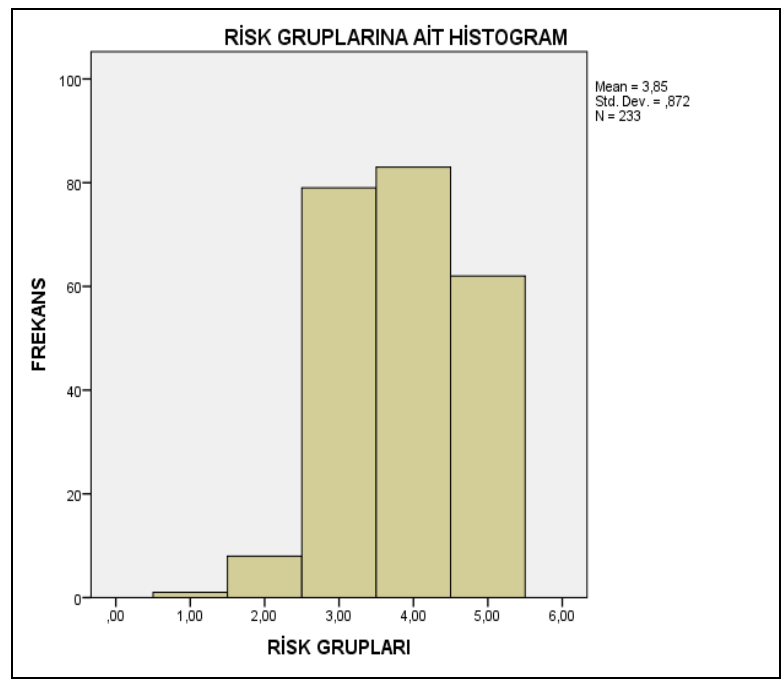

Şekil 1. Kripto Para Yatırımcılarının Risk Gruplarına Göre Dağılımlarına Ait Histogram

Yatırımcıların, finansal risk toleransı bileşenlerini oluşturan finansal risk, spekülatif risk ve yatırım riski sorularına verdikleri yanıtlar skorlanmıştır. Elde edilen skor dağılımları Tablo 10'da gösterilmiştir. Buna göre, katılımcıların finansal risk bileşeni ortalaması 20 üzerinden 11,00, spekülatif risk bileşeni ortalamas1 10 üzerinden 6,95 ve yatırım riski bileşeni ortalaması 17 üzerinden 12 olarak belirlenmiştir. 
Tablo 10. Kripto Para Yatırımcılarının Finansal Risk Bileşenlerine Ait Skorları

\begin{tabular}{|l|r|r|r|r|}
\hline & \multicolumn{1}{|c|}{ Min. Skor } & \multicolumn{2}{|c|}{ Max. Skor } & \multicolumn{2}{c|}{ Ortalama } & \multicolumn{1}{c|}{ Standart Sapma } \\
\hline Finansal Risk & 6 & 20 & 11,00 & 2,114 \\
\hline Spekülatif Risk & 3 & 10 & 6,95 & 1,995 \\
\hline Yatrrm Riski & 6 & 17 & 12 & 2,094 \\
\hline
\end{tabular}

Tablo 10'da yer alan ortalamalar, Şekil 2'deki histogram grafiklerinde gösterilmiştir.
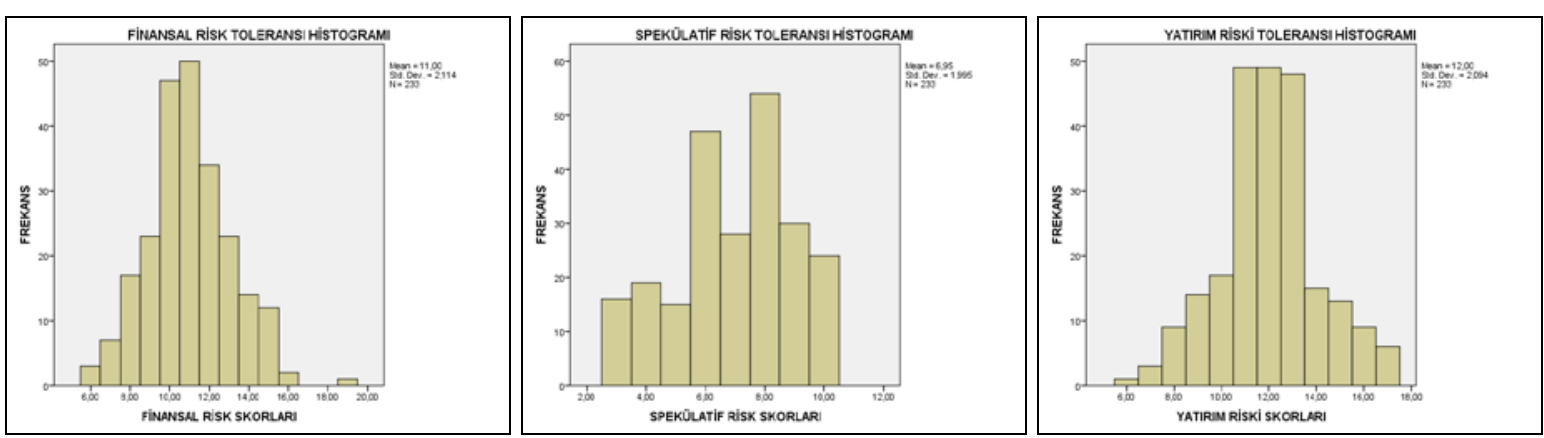

Şekil 2. Kripto Para Yatırımcılarının Finansal Risk Bileşenlerine Ait Skor Histogramlar1

Kripto para yatırımı yapan kadınlara ait örneklem mevcudunun az olması $(\% 8,2)$ sebebiyle, katılımcıların cinsiyetleri ile finansal risk toleransı ve bileşenleri (finansal risk, spekülatif risk, yatırım riski) arasındaki ilişkinin belirlenmesine yönelik herhangi bir analiz yapılamamıştır.

Yatırımcıların medeni halleri ile finansal risk toleransı ve bileşenleri arasındaki ilişkinin belirlenmesine yönelik yapılan Bağımsız Örneklem t Testi sonucunda söz konusu değişkenler arasında anlamlı bir ilişki belirlenmemiştir.

Yatırımcıların sahip oldukları çocuk sayısına göre finansal risk toleransı ve bileşenleri arasındaki ilişkinin belirlenmesine yönelik yapılan ANOVA ve Tukey Testi sonuçları Tablo 11 'de gösterilmiştir. Buna göre, kripto paraya yatırım yapan 1 çocuk sahibi bireyler ile 3 ve üzeri çocuk sahibi bireyler arasında yatırım riski bileşeni bakımından istatistiksel olarak anlamlı bir farklılık olduğu belirlenmiştir.

Tablo 11. Finansal Risk Toleransı Bakımından Kripto Para Yatırımcılarının Çocuk Sayılarına Göre ANOVA ve Tukey Testi Sonuçları

\begin{tabular}{|c|c|c|c|c|c|c|c|c|}
\hline Yatırım Riski & $\begin{array}{l}\text { Kareler } \\
\text { Toplamı }\end{array}$ & s.d. & K.O. & \multicolumn{2}{|c|}{ Tukey Testi } & $\begin{array}{c}\text { Ortalama } \\
\text { Fark }\end{array}$ & $\begin{array}{l}\text { Standart } \\
\text { Hata }\end{array}$ & $\mathbf{p}$ \\
\hline $\begin{array}{l}\text { Gruplar Arası } \\
\text { Grup İçi } \\
\text { Toplam }\end{array}$ & $\begin{array}{r}1,766 \\
38,914 \\
40,680\end{array}$ & $\begin{array}{r}3 \\
229 \\
232\end{array}$ & $\begin{array}{l}, 589 \\
170\end{array}$ & \multirow[t]{2}{*}{1 Çocuklu } & \multirow[t]{2}{*}{$\begin{array}{l}\text { Yok } \\
2 \text { Çocuklu } \\
3 \text { ve Üstü }\end{array}$} & \multirow[t]{2}{*}{$\begin{array}{r}-, 14115 \\
-, 17163 \\
-, 39487 *\end{array}$} & \multirow[t]{2}{*}{$\begin{array}{l}\text {,07144 } \\
, 08598 \\
, 12980\end{array}$} & \multirow[t]{2}{*}{$\begin{array}{l}\text {,200 } \\
\text {,192 } \\
\mathbf{0 1 4}\end{array}$} \\
\hline$F=3,464$ & $=, 017$ & & & & & & & \\
\hline
\end{tabular}

* $\alpha=0,05$ önem düzeyinde anlamlıdır. 
Eğitim düzeyleri ile genel finansal risk toleransı ve bileşenleri arasındaki ilişkinin belirlenmesine yönelik yapılan ANOVA ve Tukey Testi sonuçları Tablo 12'de gösterilmiştir. Tabloya göre, lise mezunu yatırımcılar ile üniversite mezunu yatırımcılar arasında yatırım riski bileşeni bakımından istatistiksel olarak anlamlı bir farklılık olduğu belirlenmiştir.

Tablo 12. Finansal Risk Toleransı Bakımından Kripto Para Yatırımcılarının Eğitim Düzeylerine Göre ANOVA ve Tukey Testi Sonuçları

\begin{tabular}{|c|c|c|c|c|c|c|c|c|}
\hline Yatırım Riski & $\begin{array}{l}\text { Kareler } \\
\text { Toplamı }\end{array}$ & s.d. & K.O. & & Tukey Testi & $\begin{array}{l}\text { Ortalama } \\
\text { Fark }\end{array}$ & $\begin{array}{c}\text { Standart } \\
\text { Hata }\end{array}$ & $\mathbf{p}$ \\
\hline $\begin{array}{l}\text { Gruplar Arası } \\
\text { Grup İçi } \\
\text { Toplam }\end{array}$ & $\begin{array}{r}1,677 \\
39,003 \\
40,680\end{array}$ & $\begin{array}{r}4 \\
228 \\
232\end{array}$ & $\begin{array}{l}419 \\
171\end{array}$ & \multirow[t]{2}{*}{ Lise } & \multirow[t]{2}{*}{$\begin{array}{l}\text { İlköğretim } \\
\text { Ön Lisans/Y. Okul } \\
\text { Üniversite } \\
\text { Lisansüstü }\end{array}$} & \multirow[t]{2}{*}{$\begin{array}{r}, 00585 \\
, 15716 \\
, 22234^{*} \\
, 17191\end{array}$} & \multirow[t]{2}{*}{$\begin{array}{l}19592 \\
, 10775 \\
, 07401 \\
, 09673\end{array}$} & \multirow[t]{2}{*}{$\begin{array}{r}1,000 \\
, 590 \\
\mathbf{, 0 2 4} \\
, 389\end{array}$} \\
\hline$F=2,450$ & 047 & & & & & & & \\
\hline
\end{tabular}

* $\alpha=0,05$ önem düzeyinde anlamlıdır.

Yatırımcıların meslekleri ile finansal risk toleransı ve bileşenleri arasındaki ilişkinin belirlenmesine yönelik yapılan ANOVA ve Tukey Testi sonuçları Tablo 13'te gösterilmiştir. Buna göre, özel sektörde çalışan kripto para yatırımcıları ile kamu sektöründe çalışan yatırımcılar arasında yatırım riski bileşeni bakımından istatistiksel olarak anlamlı bir farklılık olduğu belirlenmiştir.

Tablo 13. Finansal Risk Toleransı Bakımından Kripto Para Yatırımcılarının Meslek Gruplarına Göre ANOVA ve Tukey Testi Sonuçları

\begin{tabular}{|c|c|c|c|c|c|c|c|c|}
\hline Yatırım Riski & $\begin{array}{l}\text { Kareler } \\
\text { Toplamı }\end{array}$ & s.d. & K.O. & & Tukey Testi & $\begin{array}{c}\text { Ortalama } \\
\text { Fark }\end{array}$ & $\begin{array}{c}\text { Standart } \\
\text { Hata }\end{array}$ & $\mathbf{p}$ \\
\hline Gruplar Aras1 & 2,389 & 6 & ,398 & \multirow{4}{*}{$\begin{array}{l}\text { Kamu } \\
\text { Çalışanı }\end{array}$} & \multirow{4}{*}{$\begin{array}{l}\text { Özel Sek. Çalışanı } \\
\text { Emekli } \\
\text { Serbest Meslek } \\
\text { Kendi İşinde Çalışan } \\
\text { İşsiz } \\
\text { Diğer }\end{array}$} & -,19908* & ,06600 & ,045 \\
\hline Grup İçi & 38,290 & 226 & 169 & & &,- 34054 & 21130 & 675 \\
\hline Toplam & 40,680 & 232 & & & &,- 14054 & ,11655 & 891 \\
\hline$F=2,350$ & \multicolumn{3}{|l|}{$p=, 032$} & & & $\begin{array}{l}-, 26995 \\
-, 23285\end{array}$ & 12378 & , 188 \\
\hline
\end{tabular}

* $\alpha=0,05$ önem düzeyinde anlamlıdır.

Yatırımcıların kripto paralara yatırım yapma süreleri ile finansal risk toleransı ve bileşenleri arasındaki ilişkinin belirlenmesine yönelik yapılan ANOVA ve Tukey Testi sonuçları Tablo 14'te gösterilmiştir. Analiz sonuçlarına göre, 1 yıldan az süredir kripto para yatırımcısı olan bireyler ile 5 yıl ve üzerinde yatırım yapan bireyler arasında yatırım riski bileşeni bakımından istatistiksel olarak anlamlı bir farklılık olduğu belirlenmiştir.

Tablo 14. Finansal Risk Bakımından Kripto Para Yatırımcılarının Yatırım Sürelerine Göre ANOVA ve Tukey Testi Sonuçları

\begin{tabular}{|c|c|c|c|c|c|c|c|c|}
\hline $\begin{array}{l}\text { Yatırım Riski } \\
\text { Toleranst }\end{array}$ & $\begin{array}{l}\text { Kareler } \\
\text { Toplamı }\end{array}$ & s.d. & K.O. & \multicolumn{2}{|c|}{ Tukey Testi } & $\begin{array}{l}\text { Ortalama } \\
\text { Fark }\end{array}$ & $\begin{array}{l}\text { Standart } \\
\text { Hata }\end{array}$ & $\mathbf{p}$ \\
\hline $\begin{array}{l}\text { Gruplar Arası } \\
\text { Grup İçi } \\
\text { Toplam }\end{array}$ & $\begin{array}{r}2,409 \\
38,270 \\
40,680\end{array}$ & $\begin{array}{r}3 \\
229 \\
232\end{array}$ & $\begin{array}{l}803 \\
, 167\end{array}$ & \multirow[t]{2}{*}{1 Yildan Az } & \multirow[t]{2}{*}{$\begin{array}{l}1 \text { Y1l - } 3 \text { Y1l } \\
3 \text { Y1l - } 5 \text { Y1l } \\
5 \text { Y1l ve Üzeri }\end{array}$} & $\begin{array}{r}-, 15496 \\
-, 24696 \\
-, 61585^{*}\end{array}$ & $\begin{array}{l}, 06494 \\
, 11152 \\
, 19125\end{array}$ & $\begin{array}{l}, 083 \\
, 122 \\
\mathbf{0 0 8}\end{array}$ \\
\hline$F=4,806$ & \multicolumn{3}{|l|}{$p=, 003$} & & & & & \\
\hline
\end{tabular}




\section{SONUÇ VE DEĞERLENDİRME}

Kripto para yatırımcılarının finansal risk toleransları itibariyle sınıflandırılması amacıyla yapılan bu çalışmada, 13 sorudan oluşan Finansal Risk Ölçeği (Grable ve Lytton, 1999b:3) kullanılmıştır. On-line anket yöntemi kullanılarak Türkiye'de kripto para yatırımı yapan 233 katılımcıdan kolayda örnekleme yöntemiyle veri toplanmıştır. Anketlerden elde edilen skorlar hesaplanarak yatırımcılar, 1 (Düşük Risk Toleransı-Muhafazakâr Yatırımcı) ile 5 (Yüksek Risk Toleransı-Agresif Yatırımc1) arasındaki risk gruplarına göre sınıflandırılmışlardır. Sınıflandırmada Grable ve Lytton (1999b:3) tarafindan belirlenen risk grupları ve skor aralıkları esas alınmıştır.

Araştırma sonuçlarına göre, 233 kripto para yatırımcısının \%4'ünün düşük risk toleransına (muhafazakar yatırımc1), \%3,4'ünün ortalamanın altında risk toleransına, \%33,9'unun ortalama/ölçülü risk toleransına, \%35,6'sının ortalamanın üstünde risk toleransına ve \%26,6's1 yüksek risk toleransına (agresif yatırımc1) sahip oldukları belirlenmiştir. Katılımcıların genel risk toleransı ortalaması 5 puan üzerinden 3,85 olarak belirlenmiştir. Yatırımcıların \%62,2'lik kısmının ortalamanın üstünde ve yüksek risk toleransına sahip (agresif yatırımcı) bireyler oldukları belirlenmiştir.

Yatırımcıların demografik özellikleri, yatırım profilleri ile finansal risk toleransı ve bileşenleri (finansal risk, yatırım riski, spekülatif risk) arasında anlamlı ilişkinin olup olmadığını belirlemek amacıyla Bağımsız Örneklem t Testi ve Tek Yönlü ANOVA Testleri uygulanmıştır.

Kadın kripto para yatırımcısı bireylerin örneklem içindeki sayısının yetersiz olması sebebiyle analiz yapılamamıştır. Bununla birlikte, kripto para yatırımcılarının medeni halleri itibariyle finansal risk toleransı ve bileşenleri arasında anlamlı bir fark belirlenmemiştir.

Yatırımcıların yaş grupları, aylık net gelirleri, yatırım portföylerini gözden geçirme sıklıkları, yatırımlarını değerlendirdikleri kripto para türleri, yatırım yaptıkları kripto para sayısı ile finansal risk toleransı ve bileşenleri arasında anlamlı bir fark belirlenmemiştir. Diğer taraftan, tek çocuk sahibi yatırımcılar ile 3 ve üzerinde çocuk sahibi olan bireyler arasında yalnızca yatırım riski bileşeni bakımından anlamlı bir farklılık bulunduğu belirlenmiştir. Benzer şekilde, lise mezunu kripto para yatırımcıları ile üniversite mezunları arasında; kamu çalışanları ile özel sektör çalışanları arasında; 1 yıldan az süredir kripto para yatırımı yapan bireyler ile 5 yıl ve üzerinde yatırım yapmakta olan yatırımcılar arasında yalnızca yatırım riski bileşeni bakımından anlamlı bir farklılık bulunduğu, finansal risk toleransı ve diğer bileşenler bakımından anlamlı bir farklılık bulunmadığı görülmüştür.

Araştırma kapsamında ankete katılım sağlayan kadın birey sayısının az olması dikkat çeken önemli bir konudur. Literatürde her ne kadar kadın bireylerin erkeklere nispeten risk toleranslarının daha düşük seviyede olduğuna dair bulgular (Grable, 2000; Faff vd., 2008; Saraç ve Kahyaoğlu, 2011; Gibson vd., 2013; Orçun, 2015) yer alsa da kripto para yatırımı konusunda erkek bireyler kadar katılımlarının olmaması altında yatan nedenlerin araştırılmaya değer bir konu olduğu değerlendirilmektedir. Bununla birlikte, kripto para yatırımcılarının sahip oldukları çocuk sayısı, eğitim düzeyleri, kamu/özel sektör çalışanı olmaları ve kripto paraya yatırım yapma süreleri bakımından yatırım riski bağlamında 
farklılıklar göstermesinin sosyolojik, kültürel, ekonomik ve psikolojik açıdan incelenmeye değer bulgular olduğu değerlendirilmektedir.

Araştırma sonuçları, kripto para yatırımcılarının çoğunluğunun yüksek düzeyde risk almaya eğilimli erkek bireyler olduklarını göstermektedir. Kripto para piyasasının, güvencesiz, denetimsiz, volatil ve spekülatif yapıya sahip olması, altyapısı sağlam olmayan, geleceği şüpheli sanal paraların piyasadaki varlığı, saadet zinciri (ponzi) taktiği ile yatırımcıları sömüren sanal paraların piyasadaki varlığı, bazı kripto para borsalarının, elektronik cüzdanların uğradığı hacker saldırıları, birçok hükümet ve ekonomist tarafından şüpheyle yaklaşılması ve henüz genel kabul görmemiş olması vb. olumsuzluklar göz önünde bulundurulduğunda yatırımcılardaki yüksek risk alma eğilimi altında yatan nedenlerin toplumsal açıdan araştırılması önerilmektedir.

Kripto para piyasasının birçok hükümet tarafından henüz resmi olarak tanınmamış olması ve bazı otoritelerce gelecekte patlayacak bir "balon” olarak görülmesi, altyapısının henüz oturmamış olması, güvencesiz oluşu ve böylesi bir ortamda Türkiye’de yüksek risk almaya eğilimli kripto para yatırımcılarının bulunması nedeniyle konunun kamu politikası yapıcıları, sosyologlar ve ekonomistler bağlamında değerlendirilmesi önerilmektedir.

Türkiye'deki kripto para yatırımcı profilinin yüksek risk almaya eğilimli bireylerden oluşması, paranın kontrolsüz, merkeziyetsiz olması, ülkeler arasında dolaşması ve kripto para piyasasındaki tehditler düşünüldüğünde, en azından kripto para altyapısı kendisini ispat edene kadar, yatırımcıları bilgilendirici ve bilinçlendirici konferans, panel, kamu spotu gibi faaliyetlerin hükümetçe hayata geçirilmesinin milli servetin korunması ve yatırımcıların bilinçlendirilmesi adına yararlı olabileceği değerlendirilmektedir.

Benzer araştırmaların, diğer ülkelerdeki kripto para yatırımcıları üzerinde de yapılmasının literatüre katkılar yapacağı değerlendirilmektedir.

\section{KAYNAKLAR}

Alnıaçık, Barış (2018), “Kripto Paraların Dünya ve Türkiye'deki Güncel Durumu Üzerine Bir İnceleme”, Research Studies Anatolia Journal, Cilt: 2, Sayı: 4, ss. 21-30.

Aslantaş Ateş, Burcu (2016), "Kripto Para Birimleri, Bitcoin ve Muhasebesi”, Çankırı Karatekin Üniversitesi, Sosyal Bilimler Enstitüsü Dergisi, Cilt: 7, Sayı: 1, ss. 349-366.

Atik, Murat - Köse, Yaşar - Y1lmaz, Bülent - Sağlam, Fatih (2015), "Kripto Para: Bitcoin ve Döviz Kurları Üzerine Etkileri”, Bartın Üniversitesi, İ̈BF Dergisi, Cilt: 6, Sayı:11, ss. 247-261.

Ballis, Antonis - Drakos, Konstantinos (2019), “Testing for Herding in The Cryptocurrency Market”, Finance Research Letters, Article in Press.

Bilir, Hakan - Çay, Şerif (2016), "Elektronik Para ve Finansal Piyasalar Arasındaki İlişki”, Niğde Üniversitesi, İktisadi ve İdari Bilimler Fakültesi Dergisi, Cilt: 9, Sayı: 2, ss. 2131. 
Bouri, Elie - Roubaud, David - Shahzad, Syed Javad Hussain (2019), “Do Bitcoin and Other Cryptocurrencies Jump Together?”, The Quarterly Review of Economics and Finance, Journal Pre-Proof, pp. 1-30.

Dirican, Cüneyt - Canoz, İsmail (2017), “The Cointegration Relationship Between Bitcoin Prices and Major World Stock Indices: An Analysis with ARDL Model Approach”, Journal of Economics, Finance and Accounting, Vol.: 4, Issue: 4, pp. 377-392.

Dizkırıcı, Ahmet Selçuk - Gökgöz, Ahmet (2018), “Kripto Para Birimleri ve Türkiye’de Bitcoin Muhasebesi”, Journal of Accounting, Finance and Auditing Studies, Cilt: 4, Say1: 2, ss. 92-105.

Faff, R., Mulino, D., Chai, D. (2008), “Financial Risk Tolerance And Risk Aversion” Vol: 31, No: 1 pp. 1-23.

Fry, John, - Cheah, Eng-Tuck (2016), "Negative Bubbles and Shocks in Cryptocurrency Markets”, International Review of Financial Analysis, Vol: 47, pp. 343-352.

Gibson, R., Michayluk, D., Venter, G. V. (2013), "Financial Risk Tolerance: An Analysis Of Unexplored Factors” Financial Services Review, Vol.: 22, pp. 23-50.

Göde, Bilal, - Küçükşahin, Habib (2017), "Kripto Para Birimlerinin Kayıtdışı Ekonomi Üzerine Etkileri; Bitcoin Örneği”, Uluslararası Politik, Ekonomik ve Sosyal Araştırmalar Kongresi Bildiri Özetleri Kitabı, 9-11 Kasım, 2017, Ankara.

Grable, John - Lytton, Ruth H. (1999a), "Financial Risk Tolerance Revisited: The Development of a Risk Assessment Instrument” Financial Services Review. Vol.: 8, Iss.: 3, pp. 163-181.

Grable, John - Lytton, Ruth H. (1999b), “Investment Risk Tolerance Quiz Scoring Grid”, https://njaes.rutgers.edu/money/assessment-tools/investment-risk-tolerance-quiz.pdf (Erişim Tarihi: 14.05.2019).

Grable, J. E. (2000), "Financial Risk Tolerance and Additional Factors That Affect Risk Taking in Everyday Money Matters”, Journal Of Business and Psychology, Vol. 14, Issue 4, pp. 25-63.

Güleç, Tuna Can (2018), "Blockchain Tabanlı Kripto Para Birimlerinin Mevcut Durumuna Dair Finansal Analizler ve Geleceği”, Manisa Celal Bayar Üniversitesi, Sosyal Bilimler Enstitüsü, Yayımlanmış Doktora Tezi.

Gültekin, Yaşar - Bulut, Yetkin (2016), "Bitcoin Ekonomisi: Bitcoin Ekosisteminden Doğan Yeni Sektörler ve Analizi”, Adnan Menderes Üniversitesi, Sosyal Bilimler Enstitüsü Dergisi, Cilt: 3, Say1: 3, ss. 82-92.

Gültekin, Yaşar (2017), “Turizm Endüstrisinde Alternatif Bir Ödeme Aracı Olarak Kripto Para Birimleri: Bitcoin”, Güncel Turizm Araştırmaları Dergisi, Cilt: 1, Sayı: 2, ss. 96-113. 
Kaplanhan, Fatih (2018), "Kripto Paranın Türk Mevzuatı Açısından Değerlendirilmesi "Bitcoin Örneğì" ”, Vergi Sorunları Dergisi, Şubat 2018, ss. 105-124

Khalilov, Merve Can Kuş - Gündebahar, Mücahit - Kurtulmuşlar, İrfan (2017), "Bitcoin ile Dünya ve Türkiye'deki Dijital Para Çalışmaları Üzerine Bir İnceleme”, 19. Akademik Bilişim Konferans1, 8-10 Şubat 2017, Aksaray. https://pdfs.semanticscholar.org/ad26/e43d2a03ca9f7d817907c83ba6b803b945e3.pdf (Erişim Tarihi: 16.09.2019).

Koçoğlu, Şehnaz - Çevik, Yasin Erdem - Tanrı̈ven, Cihan (2016), "Bitcoin Piyasalarının Etkinliği, Likiditesi ve Oynaklığı”, İşletme Araştırmaları Dergisi, Cilt: 8, Sayı: 2, ss. 77-97

Nakamoto, Satoshi (2008), “Bitcoin: A Peer-To-Peer Electronic Cash System”. Bitcoin Whitepaper.

Orçun, Çağatay (2015), "Bireysel Yatırımcının Finansal Risk Algısı Üzerine Bir Araştırma”, Dokuz Eylül Üniversitesi, Sosyal Bilimler Enstitüsü, Yayımlanmış Doktora Tezi.

Pelster, Matthias - Breitmayer, Bastian - Hasso, Tim (2019), “Are Cryptocurrency Traders Pioneers or Just Risk-Seekers? Evidence From Brokerage Accounts”, Economics Letters, Vol: 182, pp. 98-100.

Pirinççi, Ayşe Esra (2018), "Yeni Dünya Düzeninde Sanal Para Bitcoin’in Değerlendirilmesi”, Uluslararası Ekonomi Siyaset İnsan ve Toplum Bilimleri, Cilt:1, Say1:1, ss. 45-52.

Saraç, M., Kahyaoğlu, M. B. (2011), "Bireysel Yatırımcıların Risk Alma Eğilimine Etki Eden Sosyo-Ekonomik ve Demografik Faktörlerin Analizi” BDDK Bankacılık ve Finansal Piyasalar Dergisi, Cilt : 5, Say1 : 2, ss. 135-157.

Sütçü, Cem Sefa - Aytekin, Çiğdem (2018), "Bitcoin ve Kripto Para ile İlgili Sosyal Medya Kullanıcılarının Girişimcilik Düzeyleri Üzerine Bir Araştırma”, The Turkish Online Journal Of Design, Art And Communication, Cilt: 8, Sayı: 3, ss. 466-488.

Sönmez, Asuman (2014), “Sanal Para Bitcoin”, The Turkish Online Journal Of Design, Art And Communication, Cilt: 4, Sayı: 3, ss. 1-14.

Urquhart, Andrew (2016), “The Inefficiency Of Bitcoin” Economics Letters, Vol: 148, pp. 80-82.

Yurtçiçek, Mehmet Sıddık (2015), "Hukuki Açıdan Elektronik Para”, 2. Baskı, Seçkin Yayınc1lik,

Yüksel, Armağan Ebru Bozkurt (2015), "Elektronik Para, Sanal Para, Bitcoin ve Linden Doları'na Hukuki Bir Bakış”, İstanbul Üniversitesi Hukuk Fakültesi Mecmuası, Cilt: 3, Sayı: 2, ss. 173-220.

https://tr.investing.com/crypto/currencies, (Erişim Tarihi: 29.07.2019). 
